\title{
Concurrent chemoradiotherapy with docetaxel, cisplatin, and 5-fluorouracil for T3 NO glottic carcinoma without vocal cord fixation
}

\section{Ryo Toya ( $\sim$ ryo108@kumamoto-u.ac.jp)}

Kumamoto University https://orcid.org/0000-0001-9764-5718

\section{Takahiro Watakabe}

Kumamoto University Faculty of Life Sciences School of Medicine: Kumamoto Daigaku Daigakuin Seimei Kagaku Kenkyubu Igakubu

\section{Daizo Murakami}

Kumamoto University Faculty of Life Sciences School of Medicine: Kumamoto Daigaku Daigakuin Seimei Kagaku Kenkyubu Igakubu

\section{Tomohiko Matsuyama}

Kumamoto University Faculty of Life Sciences School of Medicine: Kumamoto Daigaku Daigakuin Seimei Kagaku Kenkyubu Igakubu

\section{Tetsuo Saito}

Kumamoto University Faculty of Life Sciences School of Medicine: Kumamoto Daigaku Daigakuin Seimei Kagaku Kenkyubu Igakubu

\section{Yoshiyuki Fukugawa}

Kumamoto University Faculty of Life Sciences School of Medicine: Kumamoto Daigaku Daigakuin Seimei Kagaku Kenkyubu Igakubu

\section{Kohei Nishimoto}

Kumamoto University Faculty of Life Sciences School of Medicine: Kumamoto Daigaku Daigakuin Seimei Kagaku Kenkyubu Igakubu

\section{Yorihisa Orita}

Kumamoto University Faculty of Life Sciences School of Medicine: Kumamoto Daigaku Daigakuin Seimei Kagaku Kenkyubu Igakubu

\section{Natsuo Oya}

Kumamoto University Faculty of Life Sciences School of Medicine: Kumamoto Daigaku Daigakuin Seimei Kagaku Kenkyubu Igakubu

\section{Research}

Keywords: Head and neck cancer, Glottic carcinoma, Radiotherapy, Chemoradiotherapy, Laryngeal preservation, Elective nodal irradiation 
Posted Date: August 12th, 2021

DOl: https://doi.org/10.21203/rs.3.rs-795243/v1

License: (c) (i) This work is licensed under a Creative Commons Attribution 4.0 International License. Read Full License

Version of Record: A version of this preprint was published at Anticancer Research on December 29th, 2021. See the published version at https://doi.org/10.21873/anticanres.15474. 


\section{Abstract \\ Background}

Reports on the treatment results of chemoradiotherapy (CRT) for T3 N0 glottic carcinoma without vocal cord fixation are limited. We retrospectively evaluated the efficacy and toxicity of concurrent chemoradiotherapy (CCRT) with docetaxel, cisplatin, and 5-fluorouracil (TPF) for T3 N0 glottic carcinoma without vocal cord fixation.

\section{Methods}

Twenty-five patients were treated with TPF-CCRT. The chemotherapy consisted one or two cycles of TPF as follows: docetaxil $\left(50 \mathrm{mg} / \mathrm{m}^{2}\right)$, cisplatin $\left(60 \mathrm{mg} / \mathrm{m}^{2}\right)$, and 5 -FU $\left(600 \mathrm{mg} / \mathrm{m}^{2} /\right.$ day for 5 days). RT was delivered with a once-daily fraction of $2 \mathrm{~Gy}$ without elective nodal irradiaion (ENI). After the RT of $40 \mathrm{~Gy}$ and one cycle of chemotherapy, five patients $(20 \%)$ were judged as having no tumor regression and underwent surgery. The remaining 20 patients underwent RT with a median total dose of $66 \mathrm{~Gy}$.

\section{Results}

Of the five patients who underwent surgery after the delivery of $40 \mathrm{~Gy}$, two showed residual carcinoma pathologically and the other three were confirmed to have complete pathological response to the treatment. During the follow-up period after a series of therapies, one patient had local failure. None of the patients exhibited regional or distant failure. The 5-year local control, laryngeal preservation, and overall survival rates were $87 \%, 92 \%$, and $95 \%$, respectively. Neutropenia was frequently observed during the treatment but was manageable in all the cases. No acute toxicities of grade 5 or late toxicities $\geq$ grade 3 were observed.

\section{Conclusions}

In this study, TPF-CCRT provided excellent tumor control with acceptable toxicities. Intensive local treatment with CCRT while omitting ENI is a reasonable approach for T3 N0 glottic carcinoma without vocal cord fixation.

\section{Background}

Squamous cell carcinoma (SCC) of the glottis is the most common laryngeal cancer [1]. Since the sixth edition of the TNM staging system was proposed in 2002 by the Union for International Cancer Control (UICC), diagnostic imaging modalities such as computed tomography (CT) and magnetic resonance (MR) imaging in addition to physical examination have been required for T-staging [2,3]. The current eighth edition of the TNM staging system defines T3 disease as "tumor limited to larynx with vocal cord fixation 
and/or invades paraglottic space, and/or inner cortex of the thyroid cartilage," which has no major revisions from the sixth edition.

T3 N0 glottic carcinoma without vocal cord fixation had been categorized into early T1-T2 N0 disease before the introduction of the sixth edition of the UICC TNM staging system. Radiotherapy (RT) alone has been recognized as a standard treatment for the disease; however, its treatment outcome is not sufficient, with a 5-year local control (LC) rate of $40-50 \%[3,4]$. Chemoradiotherapy (CRT) has been used to improve treatment results and recommended in the current NCCN guidelines [5]. However, reports on the treatment results of CRT for this disease are limited.

Chemotherapy comprising of docetaxel, cisplatin, and 5-fluorouracil (TPF) is one of the widely used regimen for head and neck SCC [6-8]. A previous study suggested that concurrent CRT (CCRT) with TPF is more effective than induction chemotherapy with TPF followed by RT [9]. In the present study, we evaluated the efficacy and toxicity of CCRT with TPF for T3 NO glottic carcinoma without vocal cord fixation.

\section{Methods}

\section{Patients}

This retrospective study was approved by the institutional review board. Between February 2006 and April 2019, 26 consecutive patients with pathologically confirmed T3 glottic SCC without vocal cord fixation were treated with TPF-CCRT at our hospital. One patient was excluded from the analysis because of a coexisting advanced hypopharyngeal carcinoma. After the exclusion was made, the final study population consisted of 25 patients. Prior informed consent was obtained from all the patients for the treatment and use of their medical information in future studies. Clinical staging was performed by the institutional head and neck tumor board of radiation oncologists, otolaryngologists, and radiologists. Pretreatment examination included physical, endoscopic, and ultrasonographic exminations with or without fine-needle aspiration cytology specimens in addition to MR imaging with or without gadoliniumbased contrast agents. Whole-body CT imaging with or without $\left[{ }^{18} \mathrm{~F}\right]$-fluoro-2-deoxy-D-glucose positron emission tomography was also performed. The tumors were staged in accordance with the sixth to eighth edition of the UICC TNM staging system.

\section{Treatment}

To undergo treatment, the patients had to be 20-80 years of age; have a PS of $0-2$, have a life expectancy of at least 3 months; have adequate hematologic (white blood cell count $\geq 3500 / \mathrm{mm}^{3}$, absolute neutrophil count $\geq 2000 / \mathrm{mm}^{3}$, hemoglobin level $\geq 9.5 \mathrm{~g} / \mathrm{dl}$, and platelet count $\geq 100000 / \mathrm{mm}^{3}$ ), renal (creatinine $\leq 1.2 \mathrm{mg} / \mathrm{dl}$ and creatinine clearance $\geq 60 \mathrm{ml} / \mathrm{min}$ ), and hepatic functions (total bilirubin level of $1.5 \mathrm{mg} / \mathrm{dl}$, aspartate aminotransferase level $\leq 2 \times$ upper limit of normal [ULN], and alanine aminotransferase level $\leq 2 \times U L N$ ); and have no severe complications. Chemotherapy consisted one or two cycles of TPF. The patients received an intravenous infusion of docetaxil $\left(50 \mathrm{mg} / \mathrm{m}^{2}\right)$ for an hour on 
day 1 . More than $1 \mathrm{~h}$ after completing the docetaxel infusion, $5-\mathrm{FU}\left(600 \mathrm{mg} / \mathrm{m}^{2} /\right.$ day $)$ was delivered via continuous intravenous infusion on days $1-5$. Cisplatin $\left(60 \mathrm{mg} / \mathrm{m}^{2}\right)$ was given intravenously on day 4 [9, 10]. Subcutaneous granulocyte colony-stimulating factor was administered to patients with febrile neutropenia.

RT was delivered using a 4-MV linear accelerator. The patients underwent local irradiation with opposed lateral fields. The field size was typically $6 \times 6-7 \times 7 \mathrm{~cm}$ (median, $42 \mathrm{~cm}^{2}$ ) without elective nodal irradiation (ENI). RT was delivered with a once-daily fraction of $2 \mathrm{~Gy}$. After the delivery of $40 \mathrm{~Gy}$ and one cycle of chemotherapy, the head and neck tumor board performed an interim assessment to evaluate the tumor regression on the basis of endoscopic examination and MR imaging findings $[4,11]$. In the earlier period, five patients (20\%) were judged as having no tumor regression and underwent surgery: total laryngectomy $(n=3)$ and laryngeal preservation $(n=2)$. The remaining 20 patients underwent RT with a radical total dose of 64-70 Gy (median, 66 Gy).

\section{Follow-up}

The details of the follow-up are described elsewhere [4]. Briefly, after treatment completion, the patients were followed up every month during the first year, every 3 months during the second year, and every 6 months thereafter. Physical and endoscopic examinations were performed at each follow-up visit. Posttreatment ultrasonography, MR, and/or CT imaging were also performed within 2 months after treatment completion and every 6 months thereafter or when clinically indicated.

\section{Evaluation of outcomes and statistical analysis}

LC, laryngeal preservation (LP), and overall survival (OS) rates were calculated from treatment initiation by using the Kaplan-Meier method. The patients who underwent surgery and had a complete pathological response to the treatment were censored at the time of surgery in accordance with the previous reports of Mendenhall et al. [12]. Treatment-associated toxicities were evaluated using the Common Terminology Criteria of Adverse Events Version 5.0 (CTCAE 5.0). Statistical calculations were performed using the SPSS version 26.0 software (IBM, Armonk, NY, USA).

\section{Results}

The patients' characteristics are summarized in Table 1. The median follow-up duration was 91.8 months (range, 16.6-163.8 months). Of the five patients who underwent surgery after the delivery of $40 \mathrm{~Gy}$, two had a residual carcinoma pathologically and the other three were confirmed to have a complete pathological response to the treatment. During the follow-up period after a series of therapy, one patient had local failure and died of pneumonia, probably owing to the local recurrence. Three patients died of other diseases. None of the patients exhibited regional or distant failure. The 5-year LC, LP, and OS rates were $87 \%, 92 \%$, and $95 \%$, respectively (Fig. 1). Table 2 shows the details of acute and late toxicities $\geq$ grade 2 . Neutropenia was frequently observed during the treatment but was manageable in all the 
patients. Late toxicity of grade 1 laryngeal edema was observed in two patients (8\%). No acute toxicities of grade 5 or late toxicities $\geq$ grade 3 were observed.

Table 1

Patients' characteristics $(n=25)$

\begin{tabular}{|lll|}
\hline Characteristics & $\mathbf{n}$ & (\%) \\
\hline Age (years) & Median 66 (range, 44-78) & \\
\hline Sex & & 100 \\
Male & 25 & 0 \\
\hline Female & 0 & \\
\hline ECOG performance status & & 88 \\
\hline 0 & 22 & 8 \\
\hline 1 & 2 & 4 \\
\hline 2 & 1 & 48 \\
\hline Cycles of chemotherapy & & 52 \\
\hline 1 & 13 & \\
\hline 2 & 12 & 20 \\
\hline Radiotherapy dose (Gy) & & 68 \\
\hline 40 (followed by surgery) & 5 & 4 \\
\hline 64 & 2 & 17 \\
\hline 66 & 1 & \\
\hline 70 & & \\
\hline Abbreviations: ECOG, Eastern Cooperative Oncology Group & \\
\hline
\end{tabular}


Table 2

Details of adverse events

\begin{tabular}{|lllll|}
\hline & \multicolumn{2}{c}{ Acute toxicity, n (\%) } & Late toxicity, n (\%) \\
\cline { 2 - 5 } & Grade 2 & Grade3 & Grade 4 & Grade 2 \\
\hline Leukocytopenia & $12(48 \%)$ & $11(44 \%)$ & $1(4 \%)$ & $0(0 \%)$ \\
\hline Neutropenia & $2(8 \%)$ & $12(48 \%)$ & $7(28 \%)$ & $0(0 \%)$ \\
\hline Febrile neutropenia & $0(0 \%)$ & $3(12 \%)$ & $0(0 \%)$ & $0(0 \%)$ \\
\hline Hyponatremia & $0(0 \%)$ & $1(4 \%)$ & $0(0 \%)$ & $0(0 \%)$ \\
\hline Dermatitis & $7(28 \%)$ & $4(16 \%)$ & $0(0 \%)$ & $0(0 \%)$ \\
\hline Mucositis & $12(48 \%)$ & $4(16 \%)$ & $0(0 \%)$ & $0(0 \%)$ \\
\hline Diarrhea & $5(20 \%)$ & $0(0 \%)$ & $0(0 \%)$ & $0(0 \%)$ \\
\hline Hypothyroidism & $0(0 \%)$ & $0(0 \%)$ & $1(4 \%)$ & $1(4 \%)$ \\
\hline Laryngeal edema & $1(4 \%)$ & $0(0 \%)$ & $0(0 \%)$ & $0(0 \%)$ \\
\hline Nausea/vomitting & $4(16 \%)$ & $0(0 \%)$ & $0(0 \%)$ & $0(0 \%)$ \\
\hline Fatigue & $3(12 \%)$ & $0(0 \%)$ & $0(0 \%)$ & $0(0 \%)$ \\
\hline Anorexia & $5(20 \%)$ & $0(0 \%)$ & $0(0 \%)$ & $0(0 \%)$ \\
\hline
\end{tabular}

\section{Discussion}

Owing to the reports of the insufficient outcomes of RT alone with conventional fractionation, moreintensive treatment strategies have been used for T3 N0 glottic carcinoma without vocal cord fixation. Okumura et al. reported the treatment results of 74 patients with T3 N0 glottic carcinoma without vocal cord fixation [13]. They divided the patients into three groups according to treatment regimen as follows: accelerated fractionated RT (AFRT) with 63-65.25 Gy in 27-29 fractions (2.25-2.4 Gy per fraction, once daily) without ENI (AFRT group, $n=41$ ), CCRT using cisplatin or cetuximab with ENI of 40-46 Gy in 2023 fractions ( 2 Gy per fraction, once daily) followed by boost irradiation with 24-30 Gy in 12-15 fractions (2 Gy per fraction, once daily; CCRT group, $n=10$ ), hyperfractionated RT (HFRT) with ENI of 4046 Gy in 20-23 fractions (2 Gy per fraction, once daily) followed by boost irradiation with 24-30 Gy in 16-20 fractions (1.5 Gy per fraction, twice daily; HFRT group, $n=23$ ). The 3-year local failure and OS rates were $10 \%$ and $77 \%, 20 \%$ and $100 \%$, and $26 \%$ and $87 \%$ for the AFRT, CCRT, and HFRT groups, respectively. Murakami et al. prospectively evaluated CCRT for T2 N0 glottic carcinoma staged according to UICC TNM staging system, fifth edition [14]. The RT dose of 64 Gy was delivered with a once-daily fraction of 2 Gy using low-dose chemotherapy, including cisplatin and UFT. Of 51 cases, 24 were restaged as T3 NO without vocal cord fixation according to UICC TNM staging system, sixth edition. Their 5-year LC 
and LP rates were $62 \%$ and $83 \%$, respectively. Lin et al. evaluated the efficacy of CCRT for 17 patients with T3 glottic carcinoma [15]. Of the 17 patients, 16 (94\%) had N0 and one (6\%) had N1 disease. Nine patients (53\%) had vocal cord fixation. A median RT dose of $70 \mathrm{~Gy}$ (range, 62-72.5 Gy) was delivered with a once-daily fraction of 2-2.07 Gy using cisplatin-based chemotherapy. The 5-year LC, laryngectomy-free survival, and OS rate were $87 \%, 81 \%$, and $89 \%$, respectively. The LC, LP, and OS rates in our study were considered as equivalent to or greater than those in the previous reports.

The major acute toxicities of TPF-CRT are hematologic toxicities and mucositis. Katori et al. performed TPF-CRT for 34 patients with advanced SCC of the head and neck [9]. The chemotherapy regimens consisted of two cycles of docetaxel $60 \mathrm{mg} / \mathrm{m}^{2}$ (day 1), 5 -FU $750 \mathrm{mg} / \mathrm{m}^{2} /$ day (days 1-5), and cisplatin $70 \mathrm{mg} / \mathrm{m}^{2}$ (day 4) for induction chemotherapy ( $\mathrm{n}=15$, induction CRT group) and two cycles of docetaxel $50 \mathrm{mg} / \mathrm{m}^{2}$ (day 1), 5-FU $600 \mathrm{mg} / \mathrm{m}^{2} /$ day (days $1-5$ ), and cisplatin $60 \mathrm{mg} / \mathrm{m}^{2}$ (day 4) for CCRT $(\mathrm{n}=19$, CCRT group), which were similar to or the same as ours. The total RT doses were 64-70 Gy (mean, 66.9 Gy) for the induction CRT group and 63-74 Gy (mean, 67.8 Gy) for the CCRT group. Grade 3-4 leukocytopenia, neutropenia, and mucositis were observed in $6(40 \%), 9(60 \%)$, and 6 patients $(40 \%)$ in the induction CRT group and 10 (53\%), 8 (42\%), and 15 patients (79\%) in the CCRT group. Komatsu et al. performed TPF-CCRT for 24 patients with nasopharyngeal carcinoma [10]. Chemotherapy included two cycles of docetaxel $50 \mathrm{mg} / \mathrm{m}^{2}$ (day 1), 5 -FU $600 \mathrm{mg} / \mathrm{m}^{2} /$ day (days $1-5$ ), and cisplatin $60 \mathrm{mg} / \mathrm{m}^{2}$ (day 4), which were the same as ours. RT included ENI with 40-45 Gy followed by boost irradiation, for a total of 70 Gy. Grade 3-4 neutropenia and mucositis were observed in 10 (42\%) and 16 patients (67\%), respectively. Our results on hematologic toxicities were similar with theirs. On the other hand, our results indicated obviously milder mucositis as compared with their results, probably because we omitted ENI. Overall, the toxicities we encountered were acceptable.

Currently, ENI for levels of II, III, and IVa is recommended and widely performed for patients with T3 N0 glottic carcinoma $[16,17]$. However, T3 N0 glottic carcinoma without vocal cord fixation was previously categorized into early T1-T2 N0 disease and usually treated with RT without ENI. Regional failure after treatment completion was uncommon. We previously reported the recurrence pattern of staged or restaged T3 N0 disease without vocal cord fixation by reviewing 64 cases treated with RT with or without chemotherapy [4]. Of the 64 patients, 22 (34\%) underwent RT alone and 42 (66\%) underwent CCRT with low-dose or TPF-chemotherapy. Ten patients (16\%) underwent total laryngectomy or LP surgery after the delivery of $40 \mathrm{~Gy}$ because the tumor showed no regression. The remaining 54 patients received a total RT dose of 60-72 Gy (median, $66 \mathrm{~Gy}$ ). Eighteen patients (28\%) developed recurrence, and all of them were recorded as local failure alone. None of the patients developed regional and distant failure. Similarly, as mentioned earlier, Okumura et al. performed AFRT without ENI for 41 patients with T3 N0 glottic carcinoma without vocal cord fixation [13]. Five patients (12\%) developed disease progression. The initial recurrence site was local in three patients (7\%) and regional in only two patients (5\%). It is essential to maintain a fine balance between treatment intensity for tumor control and avoiding toxicities especially for mucositis in head and neck cancer. From this point of view, intensive local treatment with CCRT while omitting ENI is a reasonable approach for T3 NO glottic carcinoma without vocal cord fixation. 
Previously, surgery was one of the main treatment modalities for T3 glottic carcinoma, and radical RT with or without chemotherapy was performed only for selected patients [18]. Therefore, in the early part of our series, five patients underwent surgery after the delivery of $40 \mathrm{~Gy}$, but more than half of the patients were confirmed to have complete pathological response to the treatment with RT of $40 \mathrm{~Gy}$ and one cycle of TPF. Considering the excellent LC in our study, complete cure can be obtained with radical TPF-CCRT even if patients have no tumor regression at the time of interim assessment.

Our study has some limitations. First, this was a retrospective study involving a relatively small number of patients. Second, five patients underwent surgery after the delivery of $40 \mathrm{~Gy}$ and one cycle of chemotherapy. The potential bias of surgical intervention might influence our conclusions.

\section{Conclusions}

TPF-CCRT provided excellent tumor control with acceptable toxicities for T3 N0 glottic carcinoma without vocal cord fixation. Intensive local treatment with CCRT while omitting ENI is a reasonable approach for the disease.

\section{Abbreviations}

SCC

squamous cell carcinoma

UICC

Union for International Cancer Control

CT

computed tomography

MR

magnetic resonance

RT

radiotherapy

LC

local control

CRT

chemoradiotherapy

TPF

docetaxel, cisplatin, and 5-fluorouracil

CCRT

concurrent chemoradiotherapy

ENI

elective nodal irradiation

LP

laryngeal preservation 
OS

overall survival

AFRT

accelerated fractionated radiotherapy

HFRT

hyperfractionated radiotherapy

\section{Declarations}

\section{Ethics approval and consent to participate}

This study received the full approval from the institutional research ethics board of Kumamoto University Hospital (No. 2281). The requirement for individual participant consent was waived by the research ethics board.

\section{Consent for publication}

Not applicable.

\section{Availability of data and materials}

The data that support the findings of this study are available from the corresponding author, but restrictions apply to the availability of the data, which were used under license for the present study, and so are not publicly available. Data are, however, available from the authors upon reasonable request and with permission of the institutional research ethics board of Kumamoto University Hospital.

\section{Competing interest}

The authors declare that they have no competing interests.

\section{Funding}

None.

\section{Author's contributions}

RT developed the study design; collected, analyzed, and interpreted the data; performed the statistical analysis; and wrote the manuscript. TW developed the study design, collected and interpreted data; and performed the statistical analysis. DM collected and interpreted the data. TM, TS, YF, and KN developed the study design and analyzed and interpreted the data. YO and NO developed the study design and interpreted the data. All authors have read and approved the final manuscript.

\section{Acknowledgments}

Not applicable. 


\section{References}

1. Braakhuis BJ, Leemans $C R$, Visser $O$. Incidence and survival trends of head and neck squamous cell carcinoma in the Netherlands between 1989 and 2011. Oral Oncol. 2014;50:670-5.

2. Hermans R, Van den Bogaert W, Rijnders A, Doornaert P, Baert AL. Predicting the local outcome of glottic squamous cell carcinoma after definitive radiation therapy: value of computed tomographydetermined tumour parameters. Radiother Oncol. 1999;50:39-46.

3. Murakami R, Nishimura R, Baba Y, Furusawa M, Ogata N, Yumoto E, et al. Prognostic factors of glottic carcinomas treated with radiation therapy: value of the adjacent sign on radiological examinations in the sixth edition of the UICC TNM staging system. Int J Radiat Oncol Biol Phys. 2005;61:471-5.

4. Toya R, Murakami R, Murakami D, Saito T, Matsuyama T, Toya Y, et al. Radiotherapy for T3N0 glottic carcinoma without cord fixation: elective nodal irradiation or not? Oncotarget. 2017;8:79761-6.

5. National Comprehensive Cancer Network. NCCN Clinical Practice Guidelines in Oncology, Head and Neck Cancers. (Version 3. 2021).

6. Katori $\mathrm{H}$, Tsukuda M, Mochimatu I, Ishitoya J, Kawai S, Mikami Y, et al. Phase I trial of concurrent chemoradiotherapy with docetaxel, cisplatin and 5-fluorouracil (TPF) in patients with locally advanced squamous cell carcinoma of the head and neck (SCCHN). Br J Cancer. 2004;90:348-52.

7. Vermorken JB, Remenar E, van Herpen C, Gorlia T, Mesia R, Degardin M, et al. Cisplatin, fluorouracil, and docetaxel in unresectable head and neck cancer. N Engl J Med. 2007;357:1695-704.

8. Sun Y, Li WF, Chen NY, Zhang N, Hu GQ, Xie FY, et al. Induction chemotherapy plus concurrent chemoradiotherapy versus concurrent chemoradiotherapy alone in locoregionally advanced nasopharyngeal carcinoma: a phase 3, multicentre, randomised controlled trial. Lancet Oncol. 2016;17:1509-20.

9. Katori $\mathrm{H}$, Tsukuda M. Comparison of induction chemotherapy with docetaxel, cisplatin, and 5fluorouracil (TPF) followed by radiation vs concurrent chemoradiotherapy with TPF in patients with locally advanced squamous cell carcinoma of the head and neck. Clin Oncol. 2005;17:148-52.

10. Komatsu M, Arai Y, Yabuki K, Sano D, Shiono O, Sakuma Y, et al. Concurrent chemoradiotherapy with docetaxel, cisplatin and 5-fluorouracil (TPF) in patients with nasopharyngeal carcinoma. Anticancer Res. 2015;35:6861-7.

11. Toya R, Murakami R, Saito T, Murakami D, Matsuyama T, Baba Y, et al. Radiation therapy for nasopharyngeal carcinoma: the predictive value of interim survival assessment. J Radiat Res. 2016;57:541-7.

12. Mendenhall WM, Parsons JT, Mancuso AA, Pameijer FJ, Stringer SP, Cassisi NJ. Definitive radiotherapy for T3 squamous cell carcinoma of the glottic larynx. J Clin Oncol. 1997;15:2394-402.

13. Okumura M, Motegi A, Zenda S, Nakamura N, Hojo H, Nakamura M, et al. Efficacy and safety of accelerated fractionated radiotherapy without elective nodal irradiation for T3NO glottic cancer without vocal cord fixation. Head Neck. 2020;42:1775-82. 
14. Murakami R, Nishimura R, Baba Y, Yumoto E, Oya N, Yamashita Y. Concurrent chemoradiation therapy with low-dose CDDP and UFT for glottic carcinomas: evaluation using the sixth edition of the UICC TNM staging system. Acta Oncol. 2006;45:162-7.

15. Lin C, Sia E, Keller J. Concurrent chemoradiation for T3 glottic squamous cell carcinoma: a reasonable alternative to upfront laryngectomy. Adv Cancer Res Treat. 2012;2012:1-8.

16. Biau J, Lapeyre M, Troussier I, Budach W, Giralt J, Grau C, et al. Selection of lymph node target volumes for definitive head and neck radiation therapy: a 2019 update. Radiother Oncol. 2019;134:1-9.

17. Doornaert P, Terhaard $\mathrm{CH}$, Kaanders JH. Dutch National Platform Radiotherapy Head and Neck Cancer.. Treatment of T3 laryngeal cancer in the Netherlands: a national survey. Radiat Oncol. 2015;10:134.

18. Department of Veterans Affairs Laryngeal Cancer Study Group. Wolf GT, Fisher SG, Hong WK, Hillman R, Spaulding $M$, et al. Induction chemotherapy plus radiation compared with surgery plus radiation in patients with advanced laryngeal cancer. The Department of Veterans Affairs Laryngeal Cancer Study Group. N Engl J Med. 1991;324:1685-90.

\section{Figures}
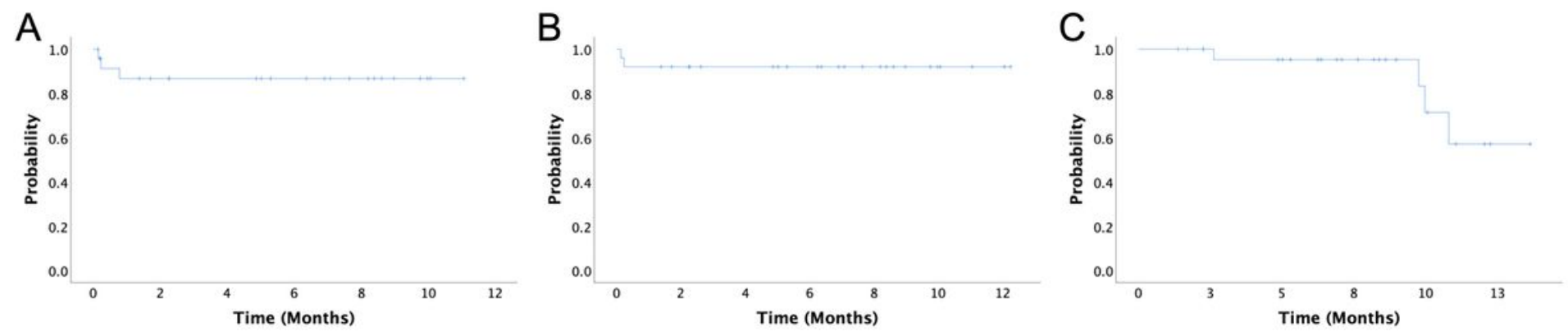

\section{Figure 1}

(A) Local control, (B) laryngel preservation, and (C) overall survival curves. 